\title{
Red Balloon, Green Balloon, Sensors in the Sky
}

\author{
Stacey Kuznetsov ${ }^{1}$, George Noel Davis ${ }^{2}$, Eric Paulos ${ }^{1}$, Mark D. Gross ${ }^{3}$, Jian Chiu Cheung ${ }^{2}$ \\ Human-Computer Interaction Institute ${ }^{1} \quad$ Department of Electrical and \\ Carnegie Mellon University \\ Pittsburgh, PA, USA \\ $\{$ stace, paulos\}@cs.cmu.edu \\ Computer Engineering ${ }^{2}$ \\ Carnegie Mellon University \\ Pittsburgh, PA, USA \\ \{gnd, jccheung\}@andrew.cmu.edu \\ Computational Design $\mathrm{Lab}^{3}$ \\ School of Architecture \\ Carnegie Mellon University \\ Pittsburgh, PA, USA \\ mdgross@cmu.edu
}

\begin{abstract}
Spectacle computing is a novel strategy for vibrantly projecting information into the public sphere using expressive and tangible media. We demonstrate an example of this computing meme with large, glowing balloons that change color based on input from attached air quality sensors (exhaust, diesel, or volatile organic compounds). In two public installations (city street and public park) and a deployment with six everyday citizens, we invited stakeholders to playfully explore and actively participate in visualizing surrounding air quality. We also created a do-ityourself (DIY) kit that includes a printed circuit board, electronic parts and instructions for building the air quality balloons. In a workshop, six non-expert users successfully assembled functional balloons, validating our technology as a DIY tool for public air quality visualization. Our deployments and workshop highlight play and spectacle as essential elements for public participation and activism. We outline design guidelines for future spectacle computing projects that engage stakeholders with environmental data and empower them to transform urban landscapes.
\end{abstract}

\section{Author Keywords}

Spectacle computing, participatory sensing, air quality

\section{ACM Classification Keywords}

H5.m. Information interfaces and presentation (e.g., HCI): Miscellaneous.

\section{General Terms \\ Design.}

\section{INTRODUCTION}

Low cost sensors, DIY (do-it-yourself) methods and bottom-up initiatives have expanded environmental sensing beyond the domain of scientists and experts, enabling ordinary citizens to measure, analyze, and share information about their environment. An emerging body of HCI and ubicomp research has explored this mode of distributed data collection by non-experts, referred to as participatory sensing [8] or citizen science [39]. Recently,

Permission to make digital or hard copies of all or part of this work for personal or classroom use is granted without fee provided that copies are not made or distributed for profit or commercial advantage and that copies bear this notice and the full citation on the first page. To copy otherwise, or republish, to post on servers or to redistribute to lists, requires prior specific permission and/or a fee.

UbiComp '11, September 17-21, 2011, Beijing, China.

Copyright 2011 ACM 978-1-4503-0630-0/11/09...\$10.00.
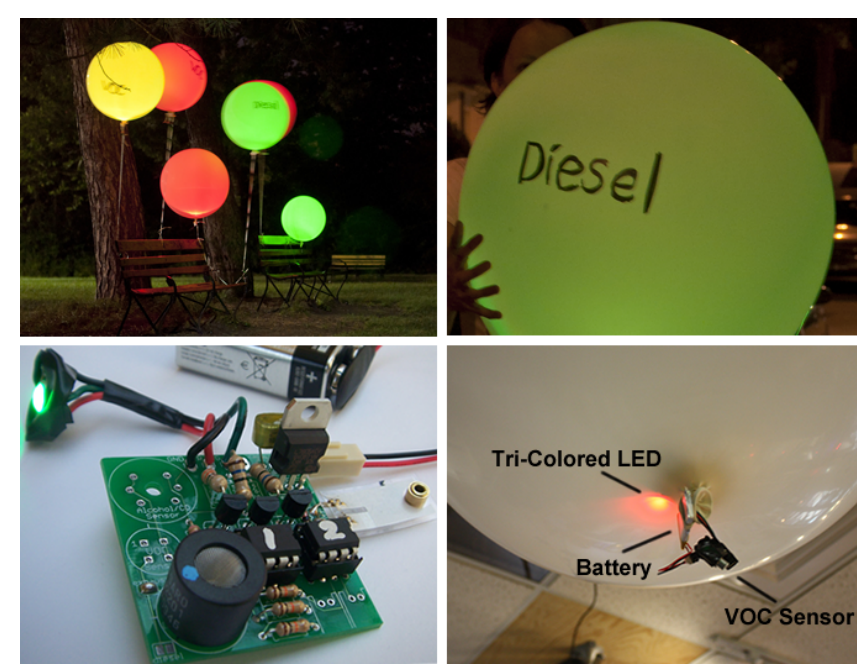

Figure 1. Air quality balloons in public park (top left), diesel balloon inflated (top right), DIY diesel kit fully assembled (bottom left), and a VOC balloon close-up (bottom right).

citizen science projects have focused on handheld devices such as cellphones and data loggers [e.g., 11] to collect environmental data, and visualizations such as graphs, charts, and maps [e.g., 16] to present this data to communities of users. We introduce spectacle computing as a playful and powerful approach to enable non-experts to view environmental data and project this information into the public sphere.

We developed large, glowing, air-quality sensing balloons as a vehicle for stakeholders to explore and reflect on urban air quality (Figure 1). The balloons change color in response to one of exhaust gas, diesel, or VOC's (volatile organic compounds). These three pollutants continue to exacerbate urban air quality problems, especially in the city where we conducted this research, where air quality has been rated as among the worst in the United States [4]. Diesel exhaust consists of fine particulate matter emitted by engines and industrial processes [44]; exhaust gas-a mixture of carbon monoxide, nitrogen dioxide, and hydrocarbons - is produced by gasoline engines [9]; and VOC's (volatile organic compounds) originate from paints, pesticides, or certain types of fuels [45]. Exposure to any of these substances can lead to chronic respiratory illnesses, not to mention the pollutants' role in global climate change. 


\section{Research objectives}

The following section describes social phenomena that inspired spectacle computing and reviews related ubicomp and HCI literature. We then detail the design of our air quality balloons and present findings from two public installations and deployments with six everyday citizens. Finally, we introduce our DIY kit, which we distributed in a workshop where six non-expert users successfully assembled functional air quality sensing balloons. Our findings offer insights into questions such as: 1) how do playful spectacles influence public perceptions of air quality; 2) how do everyday citizens use tangible media to broadcast their concerns about air quality; and 3) what are the implications of tangible media as a supporting material for DIY making and grassroots activism?

\section{SPECTACLE COMPUTING}

Artists have a long history of integrating "the spectacle" into their work: from Allan Kaprow's Happenings [27] and the writings of Guy Debord and the Situationists in the 1960's [14], to more contemporary tactical media artists such as The Yes Men, Critical Art Ensemble, RTMark, Preemptive Media, and Institute for Applied Autonomy. The Situationists differentiated between passive subjectsconsumers of the spectacle-and those who transform their own ideas, concerns, and passions into the spectacle itself. This movement applied concepts of commodity fetishism [33] to contemporary mass media to expose the common politics of its day. Spectacle computing intentionally and overtly foregrounds these ideas, using expressive technologies to inspire new thinking, curiosity and beliefs. Stakeholders who otherwise may not be aware of or care about an issue are drawn into the spectacle.

Contrary to contemporary rhetoric of "invisible" interfaces and seamless computing, we argue for a complementary strategy explicitly designed to generate spectacles. First and foremost, spectacles are difficult to ignore. The barrier to engagement is thereby effectively lowered because individuals need not download an application or carry specific hardware. The spectacle is intentionally designed to distract the individual or group's attention. Moreover, it invites people to engage in otherwise socially unacceptable behaviors such as overt public voyeurism, gossip and curiosity. Finally, it presents an acceptable context for individuals to participate in the spectacle, in the spirit of a Happening, even if such participation involves odd, unusual, or socially awkward activities (i.e. willingly taking and carrying around a glowing balloon).

We view these insights as experience design opportunities. We observe how spectacle computing moves people from a personal and private context, through public voyeurism, and into readily carrying balloons around the city, thereby creating their own spectacle. To be clear, spectacle computing is not intended to mimic the experience of yelling "fire" in a crowded theater, but to more tactfully and expressively engage public audiences in issues of personal or societal concern. While this approach is tangentially related to FlashMobs, which draw large groups of people to suddenly assemble and perform unusual acts in public places, the goal of spectacle computing is to foster discourse between stakeholders, technology and space through the use of dynamic computing elements. Also unlike FlashMobs, which may create a feeling of inclusion and exclusion, spectacle computing invites open participation from everyone.

\section{Balloons}

We use balloons as an expressive medium for creating air quality spectacles. Balloons are inherently playful: they remind us of birthday parties, water balloon fights, street fairs, weddings, or carnivals. Balloons are also functional: for decades they have enabled scientific endeavors, ranging from the NASA superpressure balloon which successfully flew over Antarctica [34] to the National Weather Service radiosondes (sensor packages) deployed on weather balloons [36], as well as a milieu of grassroots aerial photography projects [e.g., 19]. Lastly, balloons are compelling and visual: they have shaped artistic and political expressions, including the popular song 99 Luftballons [35], Lamorisse's film The Red Balloon [32], the literary work More Sky [41], and most recently, interactive balloon installations such as Open Burble [20]. This vast range of artistic and functional balloon projects inspired us to utilize large glowing weather balloons as a playful expression of a serious concern—public air quality.

\section{RELATED WORK}

Ubicomp and HCI communities have explored a range of participatory sensing platforms to enable citizens to monitor their environment. Examples include handheld sensing devices [10] cellphones [23] sensors installed in private homes [28], or sensors deployed on moving vehicles [3], bicycles [16] and pigeons [12]. Most projects employ conventional visualization methods: line graphs [28], maps [11] or numeric data [16]. More expressive and public visualizations include WearAir-a T-shirt that responds to air quality with interactive lights [29], CO2RSET - a corset that constricts when the air becomes toxic [37], the pollution e-sign, which hijacks passersby mobile phones with air quality data [24], and Air de Paris Balloon-a giant balloon tethered over the city of Paris to show data collected from several sensing stations [1]. Unlike prior work, our balloon visualization enables stakeholders to transform and produce urban lightscapes with sensor data.

\section{Urban lightscapes}

Public displays and installations such as BlueTone [13], Aarhus by Light [10], Amphibious Architecture [2], and many others have enabled stakeholders to alter urban lightscapes through sound, body movement or text messages. Modular technologies including LED Throwie's [18], Light Bodies [43], and WallBots [31] allow individuals (ranging from ordinary passersby to artists and activists) to move and place interactive elements in urban spaces. Drawing from this prior work, we created modular sensors and reactive lights carried by weather balloons. Our 
project is inspired by other creative balloon installations: Burble- a floating cloud of balloons that is controlled by moving a handlebar [20], and Wire and Balloon Installation, which responds to touch with sound [40], to name a few.

\section{Support tools for DIY practices}

A range of HCI initiatives have focused on technologies that involve communities of non-experts in hands-on making. Examples include Sketching in Hardware-a creative workshop for physical prototyping [22]; Simple Haptics - a suite of tools for creating haptic interfaces; or numerous e-textile workshops with the LilyPad as a ubiquitous tool for education $[$ e.g., 5, 6]. In addition, prior work has explored the values and practices of DIY communities through conference workshops [e.g., 7, 26], surveys [30], or qualitative fieldwork [42]. We contribute to this research by introducing a low-cost DIY kit that enables non-experts to assemble their own interactive air quality balloons. We evaluate our approach by conducting a DIY balloon-making workshop with hobbyists from a local DIY community.

\section{AIR QUALITY BALLOONS}

Our circuit is powered by a rechargeable lithium polymer battery and relies on one of two inexpensive sensors from Figaro: a VOC sensor or a dual function Diesel/Exhaust sensor [17]. The latter measures either diesel or exhaust on separate balloons, and each balloon is labeled with the corresponding pollutant ('voc', 'diesel', or 'exhaust'). PICAXE [38], a low-cost (\$1.50) microcontroller, processes sensor data and controls a tri-colored LED. This LED is inserted into the balloon; the sensor, microcontroller, and battery are mounted outside using wire and electrical tape. Balloons are illuminated based on surrounding air quality, glowing green, yellow, or red to indicate 'low', 'average', or 'high' pollution levels. Balloons are inflated using helium and their latex material naturally diffuses LED light, resulting in a large, evenly 'glowing', floating orb.

\section{Ambient light thresholds}

To support Do-It-Yourself (DIY) principles of easy access to materials and methods for creation by non-experts, we constrained the design of our system by choosing low-cost and low-fidelity sensors. We empirically determined our illumination thresholds (sensor values for green, yellow, or red balloon lighting) by gathering sensor data around Pittsburgh over the course of one week. We visited five different neighborhoods and collected readings indoors, outdoors, and at varying distances from busy streets, as well as in (traffic-free) parks. We used the observed variance in sensor output to determine thresholds below, within, and above the average sensor output for green, yellow, and red lighting respectively. Consequently, our balloons show air quality relative to the data collected in our city. Our display choice appropriately affords open interpretation through relative threshold lighting than exact numbers.

\section{AIR QUALITY SPECTACLE}

We deployed about thirty balloons throughout the city of Pittsburgh, Pennsylvania, USA over the course of one night. The authors tethered balloons around two different locations (in a public park and along a city street), observing public interactions with the installation. In addition, six stakeholders were invited to participate in our project, placing and photographing air quality balloons in public spaces throughout the city.

\section{Installations}

We selected two locations to install our air quality balloons: a public park and a city street (Figure 2), expecting to see a range of balloon colors due to different amounts of traffic, people, etc. in the two spaces. Our installation coincided with extreme humidity (over 80\%) and a PM2.5 (fine particulate matter) alert, causing many of the balloons to turn red. We inflated the balloons on site, tethering them to trees and benches (in public park) and on parking meters, cars and street signs along a city block. In addition to observing public interactions with our project we interviewed individuals who approached us and invited them to take some balloons. The installation was after dusk (around 9.30pm), so we encountered few people in the public park but numerous passersby approached us along the city block. We spent about one hour in each location.

\section{Public reactions}

Consistent with our framing of spectacle computing, nearly everyone who saw our installation was compelled to stop or slow down. In the public park and along the city block people expressed curiosity about the large, mysteriously glowing balloons. Most initial reactions suggested awe at the size and illumination: "I thought there was a party down the street", "My kids love your balloons", "Awesome balloons", etc. Most people understood the significance of the red-yellow-green lighting upon closer inspectionwhen they read the balloon labels, or after they asked us to confirm that the balloons 'showed air quality'. People reacted positively: "Keep it up, I dig it!", "Diesel exhaustthat's a very bad thing" or, "Awesome, so how can we make money with this?" Not surprisingly, individuals who
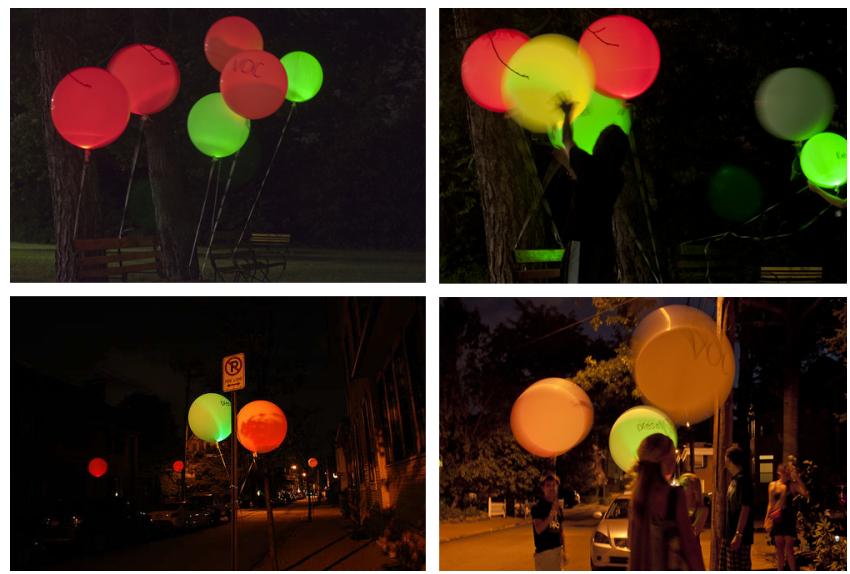

Figure 2. Air quality balloon installations in public park (top left \& right); and city street (bottom left \& right). 


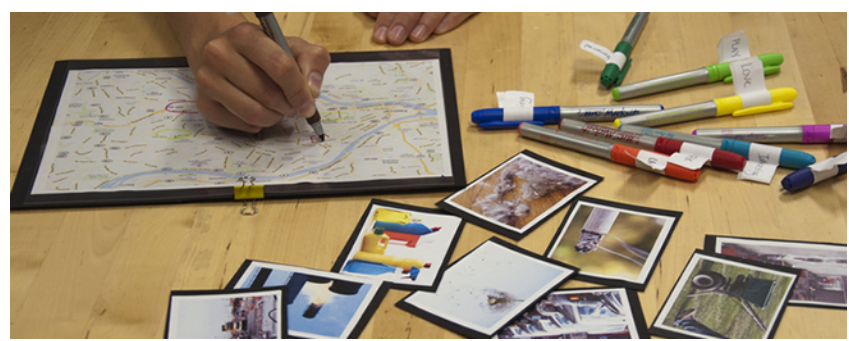

Figure 3. Interview setup: participant drawing on map transparency prior to sorting air quality factors (cards).

lived in the neighborhoods where we placed our installations related more intimately, with one person commenting:

This is my neighborhood and I know everybody, so I would probably put them [balloons] wherever I wanted. I think you should have more people with balloons...

Several people asked us if they could take a few balloons. One person excitedly pointed out:

I think anything that's big and shiny will get America's attention... I know a little bit about VOCs so I can spread the word... Word, I feel powerful now, can she [friend] have one?

Thus, when first noticing the installation, passersby reacted with excitement and curiosity. Upon further reflection, however, stakeholders began to more critically discuss the visualization, the environment, and their neighborhood. Some further speculated on the role they can play in 'spreading the word'.

\section{TAKE A BALLOON AND EXPLORE THE CITY}

In addition to our public installations, we recruited six individuals by advertising our project on Craigslist (a general-purpose classified advertising website) and local biking forums. We invited participants for a semi-structured interview exploring their relationships with urban spaces. We asked them to mark locations on a map of Pittsburgh associated with words such as "work", "play", "unhealthy", "alienating", "personal", "boring", "interesting", etc. In addition, participants identified places where they would like to monitor and broadcast air quality (Figures $3 \& 4$ ). Lastly, participants completed a card sorting exercise, ordering air quality factors such as traffic, household cleaning products, pollen, pesticides, industrial byproducts, etc., from most to least harmful for their health.

Upon completing the interview, we showed participants the air quality balloons and offered them up to three (choosing between VOC, diesel, exhaust). We encouraged participants to photograph and use the balloons as they saw fit during the course of the night: to carry them all night, leave them temporarily or permanently in a place, etc. All participants returned for a follow-up interview to share their pictures of, and experiences with, the air quality balloons. We recorded interview audio, and reference data owing to individual study participants as P1-6.

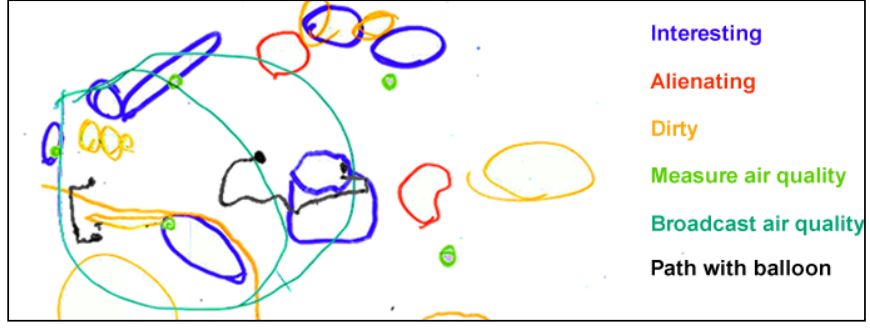

Figure 4. A subset of transparency maps drawn by a participant.

\section{Stakeholders and spaces}

Our pre-balloon interviews reveal a wide range of participants' concerns, values, and relationships with public spaces in Pittsburgh. P1 and P2 (a couple) are graduate students who spend time outdoors biking, running and playing sports such as rugby. P3 is working on a medical residency, commuting regularly by bicycle along bike trails, parks, and city streets. P4 and P5 are artists (also a couple), and P6 is a student; all three traverse the city by bus. None view themselves as political or environmental activists, and only one sporadically attends social eco-themed events. The six participants occupy very different neighborhoods, working and living in four distinct regions of Pittsburgh. Participants also have divergent perceptions of urban spaces: for instance, P1 and P2 hang out in an 'interesting' neighborhood that P3 and P4 consider 'alienating'.

Despite these differences, all participants frequent the same public parks and expect air quality to be cleaner there. They also consider the same neighborhoods to be unhealthy spaces, describing them as 'rundown', 'industrial', or having 'construction', 'traffic', or 'bad smell'. Moreover, everyone identifies vehicle traffic as the most harmful factor for health in terms of air quality. Pesticides, trash, dust, and pollen are considered least harmful because participants are less frequently exposed to these factors.

\section{Sensing and broadcasting air quality}

When asked to identify places where they would sense air quality, all participants mentioned sites they considered dirty, polluted, or unhealthy. In addition, several people wanted to monitor places they felt were clean ("I was thinking that-probably is clean there... At [park] would be more positive", P1). All participants wanted to broadcast air quality data to the general public, for instance via a 'blimp' (P4), or atop a bridge (P6), cultural district (P3), or downtown (P1\& P2). Many also suggested locations that target specific audiences. For instance, P1 and P2 suggested spaces most visible to other students:

These two [pointing on map] would be college students, because that would be the target demographic for people who'd want to change it. (P1)

Meanwhile, P3 suggested an 'eco-friendly' neighborhood:

P3: Lawrenceville, because it's full of eco-people that might be a little more aware of it. Like a little more open and receptive towards it, so people that are more 
active in it and might be more receptive to the message.

I: More receptive how? What are you thinking?

P3: People that are more willing to change behaviorso to do things about it or to tell other people about it.

\section{Balloons in the hands of urban stakeholders}

When offered the three types of balloons, five of the six participants wanted to measure VOC. P3 explained:

That's something that you can't get an idea of just visually... 'cause you know, when you're sucking in car exhaust-at least high levels, you notice that you're sucking in car exhaust. But with organic compounds, it is what it is-like you don't know.

The two couples (P1\&P2 and P4\&P5) and P6 also took an exhaust or diesel balloon. Participants brought balloons to different parts of the city: public park and downtown city center (P4\&P5), to her home and later to a party (P3), along a city street to a neighborhood where participants tend to hang out (P1\&P2), and around a college campus (P6). All six participants made an effort to visit a part of the city outside of their evening plans because of the balloons.

\section{Curiosity}

Participants reported that their balloons changed colors based on location and activity, with most people finding these changes 'interesting' or 'surprising'. Participants tended to rationalize balloon behavior: for instance, $\mathrm{P} 1$ and P2 noticed that the diesel balloon turned red whenever they put it inside their house, proposing several explanations:

P1: We came up with theories but none of them that... not necessarily impossible, but none of them even borderline likely.

I: A-ha, like what?

P1: Like the stove- the gas that we use for the stove could be producing diesel... but that doesn't make any sense. The other theory was that there's a lot of humidity in the house-like much more than outside, and the humidity... affects a lot of things.

Likewise, P3 told us that her VOC balloon reacted to doors opening and closing in her house:

I left it in my house for a couple of hours and the interesting thing was-it was red when my door was closed and green when my door was open. (P3)

P3 noted that perhaps VOC's tend to accumulate in her house due to poor ventilation:

It does make me wonder if my house worse because it's not like aerated or ventilated. (P3)

P3's friend also pointed out that the VOC balloon reacted to hair spray:

I was going to a costume party, and I was a giraffe so I had lots of hair spray going on ... and then I like-stood near it and it suddenly went like really red.
Later that night, P3 and her friends noticed the balloon turning red outside of a bar. P3 suggested that this was caused by chemicals from a nearby children's hospital.

\section{Public attention: wanted}

All six participants intentionally brought the balloons to places where they would encounter more people, reflecting positively on public attention. P2 told us:

I think they [public reactions] were pretty positive, everybody seemed pretty excited about the balloons.

Similarly, P4 noted people's immediate reaction to red balloon colors:

It caught a lot of attention, it got people almost instant awareness, especially if it was red at the time they saw it: they're like Wow! That's... concerning!!

All participants interacted with strangers, asking them to help photograph the balloons and explaining the project to passersby. Consequently, observers (passersby) began to reflect on other air quality issues in their lives. For instance:

P1: We got pictures with people, we were like 'here can you hold these' and we explained what we were doing to them'.. and then [laughing] towards the end of the night people had progressively more interest in it. We had one group ask us like in detail what we were doing and we talked to them for like 5-10 minutes.

I: And what did they say when you told them?

P1: They were like oh, that's interesting... and then one guy explained how the levels in his hometown were above what they're supposed to be because of the corporations.

Moreover, balloons inspired discussion about other expressions of air quality. P5 detailed her experience with a passerby who suggested logging and storing the data:
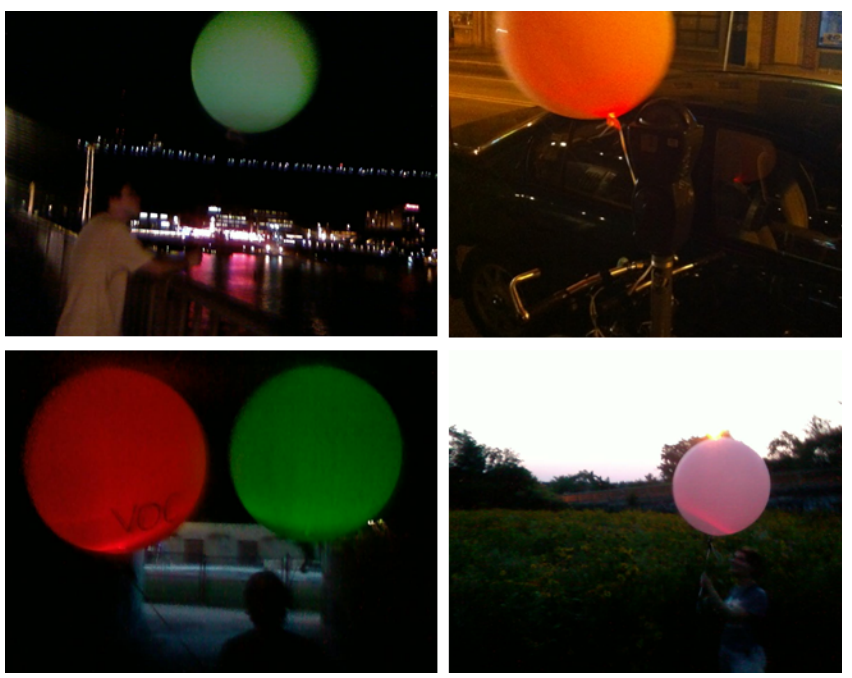

Figure 5. Air quality balloons placed by study participants: diesel balloon downtown (top left), VOC balloon near public hospital (top right), VOC \& diesel balloons in an underpass (bottom left), and VOC balloon in public park (bottom right). 
P5: One guy recommended having... an actual digital $\log$ of how it changes color, and then just having certain paths all ready that you go down. And then you could record the changes over a period of time...

P5: ... and then that would really track how things change, because I mean, just walking form one place to another, we were seeing changes left and right.

\section{Activism}

We asked participants what they would do if they could use our balloons for longer periods of time. One person (P3) wanted to place balloons all around a children's hospital to monitor VOC levels, and another suggested to permanently insteall balloons at street intersections and in public parks. Participants were skeptical about reporting this data to local authorities, with one person explaining:

I guess we usually say that we'd want to show it to the mayor, except I don't really believe in it. (P5)

Instead, people wanted to broadcast the data they collected to as many people as possible:

If you show it to just one person who's either back higher [in the government]... would just toss it away but if you get more- dozens, hundreds, thousands, millions of people, then you can get a movement. You need a ton of people to start a revolution, you can't just have one person start a revolution. (P6)

Ultimately, participants wanted to have more balloons for longer periods of time in order to collect and share data with the general public. Most participants also suggested showing data on a map, with P3 emphasizing visual (nonnumeric) representations:

I don't wanna read things like- this is however many parts per million... I just want to say like- this is bad, this is better, this needs to be better because that's all you really wanna boil it down to. (P3)

In addition, participants wanted to show data specifically to people whose behavior might be causing poor air quality:

We pretty much rely on either public transportation or a mode of walking or biking or whatever, there's really not much we can do to make less exhaust or volatile chemicals individually... But like I said, we can spread it to people who we know that may be in cars. (P4)

To summarize, our deployment with six diverse individuals inspired participants to explore new (non-routine) spaces with the balloons, as well as seek public attention and discuss the project with strangers. Reflecting on the study, participants expressed interest in using balloons for longer periods of time and in showing the visualization to other stakeholders such as eco-friendly neighborhoods or those who might be causing poor air quality.

\section{DIY AIR QUALITY BALLOON WORKSHOP}

Lastly, we created a DIY kit to enable non-experts to assemble functional air quality balloons. Here, we describe
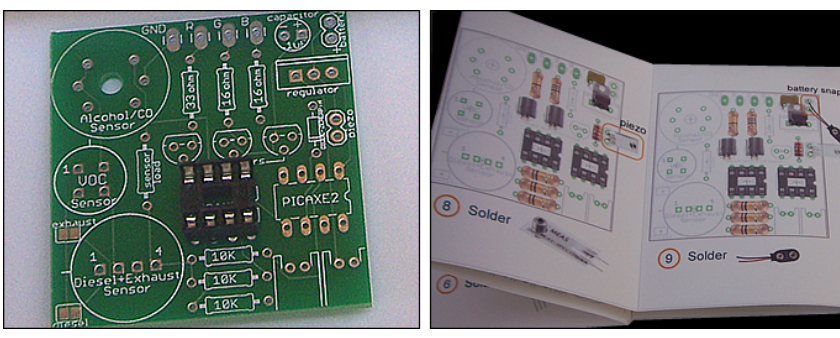

Figure 6. PCB board for the DIY balloon kit (left) and instruction booklet for assembling the board (right).

our kit and circuit board, and a workshop where six participants assembled their own working balloons.

\section{DIY balloon kit}

Our DIY balloon kit includes a custom circuit board that can be populated with a VOC or exhaust/diesel sensor. For the dual-function exhaust/diesel sensor, one of two pairs of solder pads must 'shorted' (soldered across) to supply input from either the exhaust or the diesel pin of the sensor. The board is powered by a regular 9 volt battery or two rechargeable 3.7 volt lithium ion polymer (LiPo) batteries. The circuit relies on two PICAXE-8M chips, with each modulating the pulse width of a red or a green LED channel based on input from the sensor. The PCB also supports an optional piezo vibration sensor in order to alter balloon brightness based on movement (e.g., tug on the balloon string). Similar to our earlier design, a tri-colored LED resides inside the weather balloon, connected to the PCB, which hangs below the balloon neck. The board is intentionally designed for a non-expert to assemble, with ample spacing between through-hole solder pads and all components clearly labeled (Figure 6, left). In addition, we created a booklet with step-by-step picture instructions for assembling the board (Figure 6, right). Each DIY kit costs under $\$ 25$ (VOC) or $\$ 35$ (exhaust/diesel) and includes the PCB, instruction booklet and all components (including an air quality sensor, weather balloon, tri-colored LED, piezo, two pre-programmed PICAXE chips, battery, and resistors).

\section{DIY balloon workshop}

Working with a local DIY community in Pittsburgh, we conducted a free air quality balloon-making workshop with six participants (Figure 7). The workshop began with brief discussion about attendees' backgrounds and motivations for participating. Each participant then chose one of VOC, exhaust or diesel balloon kits. Participants worked independently to assemble kits by following the included instructions, with most completing a board in about 30 minutes. Workshop organizers then assisted participants in inflating balloons and attaching batteries to the PCB (with tape). A few days later, an informal follow-up interview was conducted by phone or email to gather participants' feedback. Participants were compensated \$15 for completing this interview. We recorded audio and photographed the workshop; we reference data owing to individual workshop participants as W1-6. 


\section{Participants}

Our workshop was hosted by a local community that sponsors projects ranging from: creating hacky sack footbags by filling balloons with sand; to working with electroluminescent (EL) wire; to "yarn bombing and trying to incorporate social feedback and small bits of electronics into it" (W6); or "high altitude weather balloons to take pictures of the curvature of the earth" (W1). Workshop participants (ages mid 20's to late 30's, 5 male, 1 female) have been involved with the DIY organization for various amounts of time: more than 2 years (W1); over a year (W2, W3, W6); 6 months (W4), and just under a month (W5). Participants' backgrounds varied, including degrees and work in design, engineering and English. Participants had some familiarity with soldering and different degrees of proficiencies with electronics-from relative beginner ("other kits I've assembled were much simpler", W6; "my first introduction to soldering was the class that [DIY community] had in like September [6 months ago]", W4), to working on electronics projects on a weekly basis over the past few years (W1, W2, W3). None of the participants had previously worked with the PICAXE chip or Figaro air quality sensors. One participant owns a similar carbon monoxide sensor, but had not yet used it in a project.

\section{Motivation}

All participants indicated that they were drawn to the workshop for personal enjoyment: " a project that integrates balloons with technology is just kinda fun for us" W1; "I just thought it sounds like a really neat project" W3. Although participants were not environmental activists, some have previously thought about air quality in Pittsburgh. W5 was concerned with air and soil near his workplace:

I always kinda wonder about the soil- you know, like the lead... I wanna put this [balloon] at [work place] so people can see it as they drive over the [bridge name] bridge because it's got a lot of visibility. (W5)

Similarly, W2 noted, "I've just come to accept that Pittsburgh air quality sucks", while W3 was interested in sharing the project with his daughter:

I have a 3-year old and I'm really curious if it clicks... the concept of air pollution doesn't really mean much to her but I'm curious to see if see if with the colors it kinda clicks. (W4)

\section{Assembling the DIY balloon kit}

Most participants fully assembled their board in about 30 minutes, with only one participant taking over an hour due to a malfunctioning transistor. Throughout the workshop, participants asked several questions about the hardware ("we'll want more information about the kit-just even like the components or the source code... just because it's kinda who we are, we like to explore things." W5,), as well as a few clarification questions about the instructions (e.g., why are the steps in a certain order; or why/how to solder across the pads for the diesel/exhaust sensors). Participants were excited to turn on their balloons for the first time ("Testing the balloon! I felt like six [years old] all over again", W3; "It was really fun to see the balloon light up for the first time, to see them all together in the dark at the shop", W6)

W4 also noted that unlike kits, which require programming after assembly, the balloon kit worked immediately:

The neat thing about this kit is you come out with a functional product. We were able to play with it immediately. It wasn't like... here's the product now go write the software that does something cool. (W4)

\section{Participants' experiences with balloons}

After assembling the kits, participants were encouraged to interact with their balloons throughout the night as they saw fit. Several participants took the balloons to a restaurant, but "it was really late and we couldn't figure out where we could take them where people would be" (W5). W4 brought his balloon home to show his daughter the following day:

She and I spent some time talking about it, I tried to explain it to her... I did the exhaust, so we did talk a little bit about the smoke that comes out of cars (W4)

W3 tried to use long exposure photographs to capture his balloon changing color as he walked from a street intersection into the park (Figure 7, bottom right):

I walked from the intersection with traffic to the playground in the park to see how the colors would change. Also I figured it would make some cool pictures with long exposure... (W3)

W2 discussed the project with his friends in India:

All of us agreed that it would be a great idea to have this at several locations thorough-out Bangalore. The air quality is noticeably different in different parts of the city and the weather forecasts give pollution readings only from a few places. (W2)

Likewise, W5 hoped to initiate dialogue by sharing his
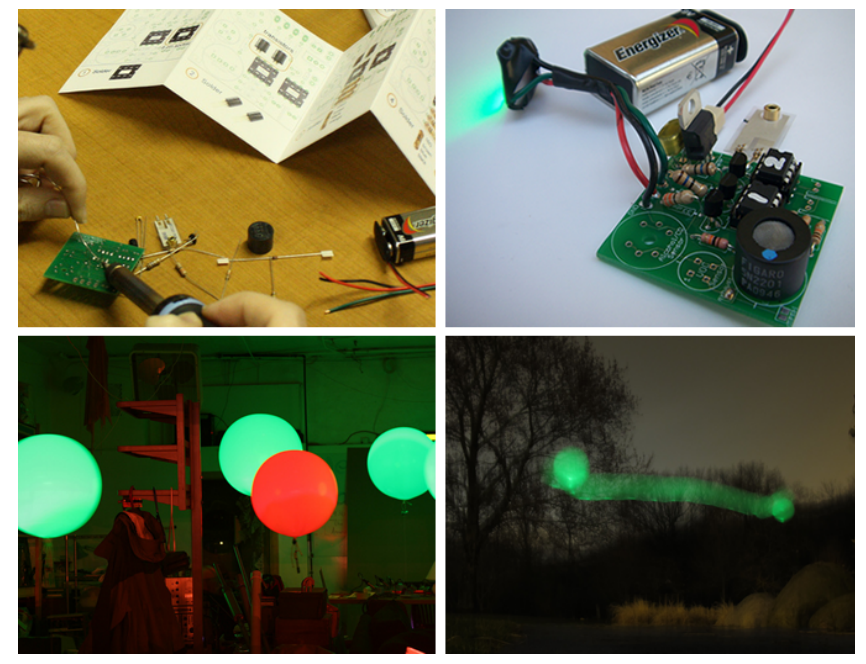

Figure 7. Workshop participant assembling a DIY balloon kit (top left); kit fully assembled (top right); fully-functional balloons built by workshop participants (bottom left); participants' long exposure photo of balloon (bottom right). 
images ("I'm hoping I can get some people responding on my Flickr pool... I think people would ask me what it's about", W5). W6, whose balloon deflated by the following afternoon speculated on using it for a whole day, "to see how and if it changed in the various places, and it would be fun to see people's reactions to it as well'. Lastly, participants had numerous ideas for modifying the kit, from adding data logging ("so you could look back and see how things changed", W6), to incorporating the kit into a "semipermanent system using plastic globes (lawn lights) on pipes" (W2). In summary, our workshop enabled six participants to assemble their own functional balloons, and interactions with the project led to exploration and speculation on expanding the project to include other functionality or be deployed in different regions.

\section{DISCUSSION}

We presented the design of our air quality sensing circuit, which was mounted on weather balloons and distributed to stakeholders to visualize concentrations of VOC's, exhaust and diesel around our city. We detailed three deployments of this technology: 1) public installations in city street and park; 2) deployment with six urban stakeholders; and 3) a workshop where six DIY hobbyists who were previously unfamiliar with the project and its underlying technology assembled functional balloons.

\section{Limitations}

We intentionally chose low-cost sensors and pursued DIY methods in order to position our technology as a tool for bottom-up movements by ordinary citizens. Admittedly, this approach does not achieve precise air quality measurements, and our work faces the limitations of inexact and un-calibrated sensors. Our visualization appropriately represents sensor readings by illuminating balloons green, yellow, or red based on whether the sensors read below, at, or above average values that were collected throughout the city. We believe there is tremendous value in communicating even these relative measurements of air quality to the public (as noted by one participant who did not want to read more detailed 'parts per million' data).

\section{DESIGN IMPLICATIONS}

We conclude with three implication areas that emerged from our work, suggesting opportunities for future research in this exciting domain of spectacle computing.

\section{The importance of play}

Our work inspired participants who were not environmental activists to assemble and interact with air quality balloons by incorporating elements of play.

\section{Playful DIY making}

Our balloon kit appealed to a local DIY community as a project that is "just kinda fun for us". The simple, clearlylabeled PCB and step-by-step image instructions enabled non-expert users to create what they considered to be "functional products", emphasizing the "fun" of "seeing the balloon light up" or feeling "like 6 [years old] again". Our findings suggest involving users in playful DIY making as an approach for inspiring environmental exploration.

Future systems can support easy assembly and modification of the underlying technology to prompt ideas for creatively augmenting the project or speculations about broader issues such as air quality, as we saw in our workshop. New, even more flexible, easy-soldering or solderless kits that can be populated with a range of sensors might spur the interest of people outside technically-minded DIY communities. Alternatively, sensors with complex underlying circuits might support easy alteration of device appearance, display, or form factor. A parallel body of research can explore intuitive instruction methods, including images, video, or in-person demonstrations. More broadly, these approaches can serve to playfully engage everyday citizens in designing and building ubiquitous technologies that monitor issues of personal concern.

\section{Playful media}

In addition, our light-hearted and playful medium (balloons) led participants to explore and discuss air quality throughout the city. During our public installations, observers began to think about air quality in their neighborhood ("diesel exhaust - that's very bad thing"). In our deployment with six everyday citizens, participants visited a park and downtown area, walked through a nearby neighborhood, and tethered the balloon to a bicycle, describing their experiences as 'fun', 'interesting', or 'surprising'. Moreover, the balloons inspired participants to question and propose theories about air quality in their surroundings: P1 and P2 wondered whether the gas from their stove was emitting diesel exhaust; P3 hypothesized that VOC levels were higher due to poor ventilation or a nearby hospital; while W3 wanted to "see how the colors would change" as he walked away from traffic.

Whereas current applications tend to rely on participants' interest in the environment, community values, or monetary compensation as motivations for sensing [e.g., 15], an alternative body of work can encourage grassroots data collection through tangible and playful media. Future systems can explore incorporating play into the experience of environmental sensing. Balloons, for instance, can be used in range of new applications: balloons tethered to a map showing data for a region; balloons that visualize other environmental factors (e.g., water quality); or large-scale projections that respond to onlookers' balloons.

Moreover, other playful objects can be appropriated as sensors to support explorations of overlooked or hard-toreach spaces (similar to Wallbots [31]). For instance, air quality sensors embedded in kites can encourage engagement with and monitoring of air quality while playing on a beach; remote-controlled boats, outfitted with water quality sensors might inspire fun investigations of local water sources; or digging toys that include soil sensors could support interactive play with soil. Future applications may also leverage familiar platforms (e.g., mobile phones) 
to distribute games and contests that motivate playful engagement with and reflection on the environment.

\section{The power of spectacle}

Air quality balloons enabled us and our participants to create spectacles. Our installations in public locations have attracted onlookers to approach the exhibit, ask questions, and voice their opinions. Participants who received working balloons actively sought attention by bringing balloons to busier streets and inviting strangers to photograph and discuss the project. Moreover, our workshop participants who assembled their own balloons, tried to bring them "where people would be", sharing the project with friends, family and strangers (through Flickr). The balloons served as boundary objects, engaging people from different communities, backgrounds, and geographic locations in environmental discourse: one observer recommended recording "changes over a long period of time" to P5, another passerby told P1 about 'the levels in his hometown'; W4 used the balloon to illustrate the "concept of air pollution" with his daughter, while W2 and his friends discussed having balloons in "several locations thoroughout Bangalore"; passersby who saw our public installations suggested having "more people with balloons", requesting to take balloons to "spread the word".

Our unconventional, vibrant, and public balloons served as entry points for environmental discourse among a diverse range of stakeholders. The installations and participants' experiences with balloons encouraged speculations about air quality between parents and children, local and international groups of friends, as well as complete strangers, either in person or by commenting on online repositories of images. These findings suggest opportunities to leverage spectacle computing for supporting new interactions between people, technology, and space.

For instance, people with vested interests in a location (e.g., homeowners) might prefer longer-term environmental spectacles in their neighborhood to facilitate local discourse, or "community togetherness" [15]. Alternatively, individuals who traverse different parts of the city (runners or postal workers) might benefit from modular platforms (e.g., Feral Robotic Dogs [25]), which support spectacles and discussions across locations. Moreover, drawing from our workshop participants' willingness to modify the balloon kit (with data logging, or different form factors such as plastic globes), future systems can allow DIY modification and re-appropriation of the spectacle. Finally, the limitations of spectacles remain to be explored. When (if ever) do glowing balloons and other similar installations cease to be enticing? How can the effectiveness of spectacles be extended to inspire environmental discourse over longer periods of time?

\section{Tangible media as an instrument of change}

Emerging HCI research continues to explore the methods and processes of activist groups [e.g., 21] in order to inform the design of technologies for political change. We contribute to this work by introducing a technology that can be assembled by non-experts to make information about air quality not only measurable and visible, but also compelling and hard to ignore. Although none of our participants were activists per se, they saw opportunities to use air quality balloons to catalyze change. From wanting to show the balloons to an "eco-friendly neighborhood", "students", and "drivers", to discussing the project with friends abroad or the general public at large, participants hoped to project collected data to other stakeholders who might be willing to take action.

Our findings suggest opportunities to use tangible media as a support tool for grassroots movements. On one hand, other new and unexpected media may effectively entice and empower bottom-up data collection: paper airplanes, remote-control cars, dog collars, baby strollers, tree leaves, or roller skates, to name a few, might serve as novel vehicles for environmental sensing (similar to street sweepers or pigeons [3, 12]). Data collected by such distributed means might be aggregated into more traditional representations (e.g., maps, graphs) to serve as political artifacts.

Alternatively, tangible media might enable users to project data within and across urban spaces in more playful and unconventional ways. Wireless communication between visualizations (e.g., balloons) and sensors can support spectacles that are physically removed from the locations being sensed. Users could place vibrant nodes in remote spaces to draw the attention of activist communities, policy makers or the general public to local issues.

\section{CONCLUSION}

We explored spectacle computing as an approach for vibrantly projecting data into the public sphere and inspiring environmental discourse. In two public installations and a deployment with six everyday citizens we evaluated a novel technology-large balloons that glow, based on surrounding air quality. In addition, our kit enabled six members of a local DIY community to assemble their own, fully functional balloons. We leverage our findings to propose play and spectacle as essential elements for inspiring public discussion within and across communities of stakeholders. We hope that our work inspires other spectacle computing projects that engage passive onlookers, routine visitors, and avid activists in political and environmental discourse.

\section{ACKNOWLEDGEMENTS}

We thank all our participants for their feedback. Financial support for this research was provided in part by the Heinz Endowment. We thank our reviewers for their thoughtful feedback, which will continue to shape our future research.

\section{REFERENCES}

1. Aerophile, S.A. Air de Paris balloon. http://aerophile.com/

2. Amphibious Architecture by The Living Architecture Lab at Columbia University Graduate School of Architecture, September 17 - November 7, 2009. www.sentientcity.net 
3. Aoki, P. M., Honicky, R. J., Mainwaring, A., Myers, C. Paulos, E. Subramanian, S. Woodruff, A. A vehicle for research: using street sweepers to explore the landscape of environmental community action. CHI 2009, p. 375-384.

4. American Lung Association. City Rankings 2010: Most Polluted Cities. http://www.stateoftheair.org/2010/

5. Buechley, L., Eisenberg, M. (2009) Fabric PCBs, Electronic Sequins, and Socket Buttons: Techniques for Etextile Craft. Journal of Personal and Ubiquitous Computing, 13(2), p. 133-150.

6. Buechley, L., Eisenberg, M. (2008). The LilyPad Arduino: Toward Wearable Engineering for Everyone. Wearable Computing Column in IEEE Pervasive, v.7 n.2, p.12-15.

7. Buechley, L., Rosner, D., Paulos, E., and Williams, A. (2009). Workshop: DIY for CHI: methods, communities, and values of reuse and customization. In Proceedings of the 27th international conference extended abstracts on Human factors in computing systems (CHI EA '09). ACM, New York, NY, USA, 4823-4826.

8. Burke, J., Estrin, D., Hansen, M., Parker, A., Ramanathan, N., Reddy, S., Srivastava, M.B. Participatory Sensing. In World Sensor Web Workshop. ACM, 2006.

9. Coalition for Clean Air. Pollutants \& Health Effects. http://www.coalitionforcleanair.org.

10. Brynskov, M. Aarhus by Light. 2010. http://www.aarhusbylight.dk/index-english.html

11. Da Costa, B., Schulte, J., and Singer, B. AIR - Area's Immediate Reading. http://www.pm-air.net

12. Da Costa, B., Hazegh, C., Ponto, K. Pigeon blog. http://www.pigeonblog.mapyourcity.net

13. Dearman, D., Truong, K. N. 2009. BlueTone: a framework for interacting with public displays using dual-tone multifrequency through bluetooth. In Ubicomp '09, p. 97-100.

14. Debord, G. The Society of the Spectacle. Zone, 1994.

15. DiSalvo, C. Marti, L., Coupland, J., Steiner, M. A 2009. Local Issues, Local Uses: Tools for robotics and sensing in community contexts. Creativity \& Cognition, p. 245-254.

16. Eisenman, S. B., Miluzzo, E., Lane, N. D., Peterson, R. A., Ahn, G., and Campbell, A. T. 2009. BikeNet: A mobile sensing system for cyclist experience mapping. In Proceedings of SenSys '07. p. 87-101.

17. Figaro Gas Sensors. http://www.figarosensor.com/

18. Graffiti Research Lab. Throwies. graffitiresearchlab.com

19. Grassroots Mapping. Balloon Aerial Photography.

20. Haque, U. Burble, London, UK 2007, http://www.haque.co.uk/burblelondon.php

21. Hirsch, T., Henry, J. 2005. TXTmob: text messaging for protest swarms. In CHI '05 extended abstracts on Human factors in computing systems (CHI EA '05), p. 1455-1458.

22. Holmquist, L. E.. 2006. Sketching in hardware. Interactions 13, 1 (January 2006), p. 47-60.

23. Honicky, R., Brewer, E. A., Paulos, E., and White, R. 2008. N-smarts: networked suite of mobile atmospheric real-time sensors. ACM SIGCOMM Workshop on Networked Systems For Developing Regions, 2008.
24. Hooker, B., Gaver, W.W., Steed, A., \& Bowers, J. The Pollution e-Sign. Workshop on Ubiquitous Sustainability. Ubicomp, 2007.

25. Jeremijenko, N., Arnold, J. J., Kavesh, W. Feral Robotic Dogs. 2009.

26. Kaye, J., Williams, A., Oehlberg, L. Tinkering, Crafts and Inventive Leisure Practices. In proceedings of the 2011 conference on Computer Supported Cooperative Work.

27. Kaprow, A. Assemblages, Environments \& Happenings, Harry N. Abrams, Inc.Publishers, New York, 1966.

28. Kim, S. and Paulos, E. 2009. inAir: measuring and visualizing indoor air quality. Ubicomp '09, p. 81-84.

29. Kim, S., Paulos, E., and Gross, M. D. 2010. WearAir: expressive t-shirts for air quality sensing. In Proceedings of the fourth international conference on Tangible, embedded, and embodied interaction (TEI '10), p. 295-296

30. Kuznetsov, S. Paulos, E.. 2010. Rise of the expert amateur: DIY projects, communities, and cultures. In Proc. of the 6th Nordic Conference on Human-Computer Interaction: Extending Boundaries (NordiCHI '10), p. 295-304

31. Kuznetsov, S., Paulos, E, Gross, M.D. WallBots: Interactive Wall-Crawling Robots In the Hands of Public Artists and Political Activists. In Proc. of the 8th ACM Conference on Designing Interactive Systems (DIS '10). ACM, New York, NY, USA, 208-217.

32. Lamorisse, A. The Red Balloon.

33. Marx, L. 1867. The Fetishism of Commodities and the Secret thereof. Das Kapital (1867).

34. NASA. New NASA Balloon Successfully Flight-Tested Over Antarctica, December 2009. www.nasa.gov

35. Nena. 99 Luftballons. Released in 1983.

36. NOAA National Weather Service. Radiosonde Observations. http://www.ua.nws.noaa.gov/

37. OFriel, K., CO2RSET. itpedia.nyu.edu/wiki/CO2RSET

38. PICAXE. http://www.rev-ed.co.uk/picaxe/

39. Paulos, E., Honicky, R.J., Hooker, B. Citizen Science: Enabling Participatory Urbanism. Handbook of Research on Urban Informatics, 2008.

40. Pete's Sonic Art Research. Wire and Balloon Installation. http://petes-sonic-art-research.blogspot.com/

41. Piene, O. More Sky. MIT Press, 1973.

42. Rosner, D., Bean, J. 2009. Learning from IKEA hacking: I'm not one to decoupage a tabletop and call it a day. In Proceedings of the 27th international conference on Human factors in computing systems (CHI '09), p. 419-422.

43. Seitinger, S., Taub, D. M., Taylor, A. S. 2010. Light bodies: exploring interactions with responsive lights. In Proc. of the fourth international conference on Tangible, embedded, and embodied interaction (TEI '10), 113-120.

44. U.S. EPA. Health Assessment Document for Diesel Engine Exhaust. U.S. Environmental Protection Agency, 2002

45. U.S. EPA.Volatile Organic Compounds. http://www.epa.gov/air/emissions/voc.htm 